\title{
The place of dexmedetomidine light sedation in patients with acute brain injury
}

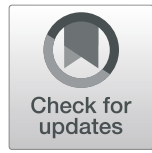

\author{
Simone Carelli ${ }^{1,2^{*}}$ (D), Gennaro De Pascale ${ }^{1,2}$, Nicoletta Filetici ${ }^{1,2}$, Maria Grazia Bocci ${ }^{1,2}$, Gian Marco Maresca ${ }^{1,2}$, \\ Salvatore Lucio Cutuli ${ }^{1,2}$, Cecilia Maria Pizzo ${ }^{1,2}$, Giuseppe Bello ${ }^{1,2}$, Luca Montini ${ }^{1,2}$, Anselmo Caricato ${ }^{1,2}$, \\ Giorgio Conti ${ }^{1,2}$ and Massimo Antonelli ${ }^{1,2}$
}

To the Editor,

An individualized titration of sedative and analgesic drugs is pivotal in the late phase management of acute brain injury (ABI) patients, when weaning from mechanical ventilation (MV) needs to be implemented [1]. Due to its pharmacologic profile, dexmedetomidine (Dex) represents a drug of choice in such setting. Nevertheless, its use in ABI patients has been recently debated mainly as a consequence of its hemodynamic effects $[2,3]$. The present study aimed to evaluate clinical outcomes and safety profile of Dex administration in this patients' category.

We retrospectively analysed prospectively collected data on the main clinical features and adverse events observed during light sedation with dexmedetomidine (Dex-LS) in ICU patients with ABI. Light sedation was defined by the maintenance of a Richmond Agitation and Sedation Scale (RASS) score between 1 and -2 . The rate of potential side effects during Dex-LS was compared with the 6-h period before Dex initiation (see Additional file 1 for further details).

The main clinical and analgosedation characteristics of the 101 included patients are listed in Table 1. Traumatic ABI (77.2\%) was the main admission diagnosis, and haemorrhage $(59.4 \%$ of the cohort) was the most common admission feature (see Additional file 1: Table S1). Out of 101 patients, 80 were mechanically ventilated during Dex-LS. In most cases, dexmedetomidine was administered in association with other sedatives, opioids or antipsycotic drugs, for a median duration and dosage of $64 \mathrm{~h}$ and $0.6 \mu \mathrm{g} / \mathrm{kg} / \mathrm{h}$, respectively.

Dexmedetomidine has been administered safely in our population of ABI patients. Dex infusion rate and duration were comparable with those previously described [2, 3]. The rate of systemic arterial hypotension was consistent with available findings [2, 3] and lower compared with the pre-infusion period. The $23 \%$ rate of bradycardia takes place in the wide range of occurrence reported in ABI patients [2]. Nevertheless, bradycardia never imposed dexmedetomidine interruption. These findings should be interpreted in the light of the relatively young age and low severity scores of our population, where Dex was frequently co-infused with other sedatives or opioids. Neither seizure rate nor intracranial pressure increased during Dex-LS, supporting the clinical absence of Dex impact on cerebral physiology [4].

During Dex-LS, the majority of patients were weaned from MV, including more than half who previously failed a weaning attempt. These observations are in line with the available evidence comparing Dex sedation with midazolam and propofol use, even though in ICU patients without $\mathrm{ABI}$ [5].

In conclusion, despite the intrinsic limitations of our retrospective design lacking a control group, this study suggests that when used to target light sedation in our cohort of ABI patients, dexmedetomidine was safe and enabled the weaning from MV and the maintenance of spontaneous breathing.

\footnotetext{
* Correspondence: simonecarelli.sc@gmail.com

${ }^{1}$ Istituto di Anestesiologia e Rianimazione, Università Cattolica del Sacro

Cuore, Rome, Italy

2Dipartimento di Scienze dell'Emergenza, Anestesiologiche e della

Rianimazione, Fondazione Policlinico Universitario A. Gemelli IRCCS, Rome, Italy
}

(c) The Author(s). 2019 Open Access This article is distributed under the terms of the Creative Commons Attribution 4.0 International License (http://creativecommons.org/licenses/by/4.0/), which permits unrestricted use, distribution, and reproduction in any medium, provided you give appropriate credit to the original author(s) and the source, provide a link to the Creative Commons license, and indicate if changes were made. The Creative Commons Public Domain Dedication waiver (http://creativecommons.org/publicdomain/zero/1.0/) applies to the data made available in this article, unless otherwise stated. 
Table 1 Features of 101 patients undergoing Dex-LS

\begin{tabular}{|c|c|c|c|}
\hline \multicolumn{4}{|l|}{ Clinical characteristics } \\
\hline Age, years & \multicolumn{3}{|l|}{$53[35-68]$} \\
\hline Male & \multicolumn{3}{|l|}{$84(83.2)$} \\
\hline Neuro-psychiatric comorbidities & \multicolumn{3}{|l|}{$24(23.8)$} \\
\hline - Preesistent psychosis & \multicolumn{3}{|l|}{$12(11.9)$} \\
\hline - Preesistent dementia & \multicolumn{3}{|l|}{$5(5)$} \\
\hline - Preesistent epilepsy & \multicolumn{3}{|l|}{$7(6.9)$} \\
\hline Traumatic brain injury (TBI) & \multicolumn{3}{|l|}{$78(77.2)$} \\
\hline - Isolated traumatic brain injury & \multicolumn{3}{|l|}{$14(13.8)$} \\
\hline - Polytrauma with traumatic brain injury & \multicolumn{3}{|l|}{$64(63.4)$} \\
\hline Non-traumatic brain injury & \multicolumn{3}{|l|}{$23(22.8)$} \\
\hline ISS at admission (TBI only) & \multicolumn{3}{|l|}{23 [17-29] } \\
\hline Head-AIS at admission (TBI only) & \multicolumn{3}{|l|}{$3[2-4]$} \\
\hline GCS at admission* & \multicolumn{3}{|l|}{$10[7-14]$} \\
\hline SAPS II at Dex-LS start & \multicolumn{3}{|l|}{$34[26-44]$} \\
\hline SOFA at Dex-LS start & \multicolumn{3}{|l|}{$4[3-7]$} \\
\hline MV at admission & \multicolumn{3}{|l|}{$91(90.1)$} \\
\hline MV at Dex-LS start & \multicolumn{3}{|l|}{$80(79.2)$} \\
\hline ICU LOS pre-Dex-LS, days & \multicolumn{3}{|l|}{$4[2-8]$} \\
\hline ICU LOS post-Dex-LS, days & \multicolumn{3}{|l|}{$8[3-15]$} \\
\hline ICU mortality & \multicolumn{3}{|l|}{$4(4)$} \\
\hline Hospital mortality & \multicolumn{3}{|l|}{$8(7.9)$} \\
\hline Hours of $\mathrm{MV}^{\#}$ & \multicolumn{3}{|l|}{39 [12-72] } \\
\hline MV in assisted mode ${ }^{\#}$ & \multicolumn{3}{|l|}{$71(88.8)$} \\
\hline MV in assisted mode, hours" & \multicolumn{3}{|l|}{$24[6-48]$} \\
\hline Successful weaning ${ }^{\#}$ & $56(70)$ & & \\
\hline Successful weaning in pts with previous weaning failure ${ }^{\# \#}$ & $16(57.1)$ & & \\
\hline Spontaneous breathing, hours ${ }^{\#}$ & $25[0-72]$ & & \\
\hline Analgosedation details & & & \\
\hline RASS & $0[-1 / 0]$ & & \\
\hline Propofol co-infusion & $35(34.7)$ & & \\
\hline Midazolam co-infusion & 0 & & \\
\hline Remifentanil co-infusion & $59(58.4)$ & & \\
\hline Other opioids co-infusion** & $15(14.9)$ & & \\
\hline Antipsychotic drugs co-administration*** & 40 (39.6) & & \\
\hline Dex length of infusion, hours & $64[33-120]$ & & \\
\hline Dex start dosage, $\mu \mathrm{g} / \mathrm{kg} / \mathrm{h}$ & $0.7[0.5-0.9]$ & & \\
\hline Dex median dosage, $\mu \mathrm{g} / \mathrm{kg} / \mathrm{h}$ & $0.6[0.5-0.9]$ & & \\
\hline Dex maximum dosage, $\mu \mathrm{g} / \mathrm{kg} / \mathrm{h}$ & $0.9[0.6-1.2]$ & & \\
\hline Dex dosage at suspension, $\mu \mathrm{g} / \mathrm{kg} / \mathrm{h}$ & $0.5[0.3-0.8]$ & & \\
\hline Hemodynamic parameters and adverse events $(n=101)$ & & & \\
\hline & Pre-Dex infusion ${ }^{\# \#}$ & Dex-LS & $P$ value \\
\hline RASS & $-2[-3 / 0]$ & $0[-1 / 0]$ & $<0.001$ \\
\hline $\mathrm{HR}$, bpm & 78 [70-89] & $80[66-91]$ & 0.165 \\
\hline $\mathrm{SAP}, \mathrm{mmHg}$ & $133[124-146]$ & 139 [126-150] & 0.136 \\
\hline
\end{tabular}


Table 1 Features of 101 patients undergoing Dex-LS (Continued)

\begin{tabular}{llll}
\hline DAP, $\mathrm{mmHg}$ & $65[56-72]$ & $69[62-78]$ & $<0.001$ \\
MAP, $\mathrm{mmHg}$ & $85[78-98]$ & $90-99]$ & $23(22.8)$ \\
Bradycardia & $2(2)$ & $12(20.3)$ & $<.039$ \\
- Bradycardia in pts receiving remifentanil co-infusion & - & $0.6[0.4-0.9]$ \\
- Dex median dosage in pts with bradycardia, $\mu \mathrm{g} / \mathrm{kg} / \mathrm{h}^{\wedge \wedge}$ & - & $27(26.7)$ & - \\
Arterial hypotension requiring vasopressors & $42(41.6)$ & $3(3)$ & - \\
Seizures & $3(3)$ & $8[7-10]$ & 0.037 \\
$\mathrm{ICP}, \mathrm{mmHg}^{*}$ & $9[8-14]$ & 0.164 \\
\hline
\end{tabular}

Dex dexmedetomidine, LS light sedation, ISS Injury Severity Score, AIS Abbreviated Injury Scale, GCS Glasgow Coma Scale, SAPS II Simplified Acute Physiology Score II, SOFA Sequential Organ Failure Assessment, MV mechanical ventilation, LOS length of stay, RASS Richmond Agitation-Sedation Scale, HR heart rate, SAP systolic arterial pressure, DAP diastolic arterial pressure, MAP mean arterial pressure, ICP intracranial pressure, pts patients Data are shown as median [IQR] or $N(\%)$

*GCS at admission was available in 96 patients. ICP was monitored in 10 patients

**Sufentanil, morphine

***Haloperidol, quetiapine, chlorpromazine

\#Eighty out of 101 patients were mechanically ventilated during Dex-LS

\#\#Twenty-eight patients failed at least a weaning attempt before Dex-LS

\#\#\#Data of 6-h pre-Dex infusion period were analysed

${ }^{\wedge}$ Fifty-nine patients received remifentanil co-infusion

${ }^{\wedge}$ Twenty-three patients had bradycardia event(s)

\section{Supplementary information}

Supplementary information accompanies this paper at https://doi.org/10. 1186/s13054-019-2637-9.

Additional file 1. Electronic Supplementary Material.

\section{Acknowledgements}

Not applicable.

\section{Authors' contributions}

MA, GDP and SC conceived and designed the study. All the authors significantly contributed to acquire, analyse and interpret the data and cooperated to draft the manuscript. They all read and approved the present final version.

\section{Funding}

None

\section{Availability of data and materials}

The datasets used and/or analysed during the current study are available from the corresponding author on reasonable request.

\section{Ethics approval and consent to participate}

The study was approved by the ethics committee of the Catholic University of the Sacred Heart (Prot. UCSC34998/18). Due to its observational, noninterventional design, informed consent was waived.

\section{Consent for publication}

Not applicable.

\section{Competing interests}

The authors declare that they have no competing interests.

Received: 18 July 2019 Accepted: 2 October 2019

Published online: 01 November 2019

\section{References}

1. Oddo M, Crippa IA, Mehta S, Menon D, Payen JF, Taccone FS, et al. Optimizing sedation in patients with acute brain injury. Crit Care. 2016;20: 128.

2. Tsaousi GG, Lamperti M, Bilotta F. Role of dexmedetomidine for sedation in neurocritical care patients: a qualitative systematic review and meta-analysis of current evidence. Clin Neuropharmacol. 2016;39:144-51.
3. Humble SS, Wilson LD, Leath TC, Marshall MD, Sun DZ, Pandharipande PP, et al. ICU sedation with dexmedetomidine after severe traumatic brain injury. Brain Inj. 2016;30:1266-70.

4. James ML, Olson DM, Graffagnino C. A pilot study of cerebral and haemodynamic physiological changes during sedation with dexmedetomidine or propofol in patients with acute brain injury. Anaesth Intensive Care 2012:40:949-957.

5. Jakob SM, Ruokonen E, Grounds RM, Sarapohja T, Garratt C, Pocock SJ, et al. Dexmedetomidine vs midazolam or propofol for sedation during prolonged mechanical ventilation: two randomized controlled trials. JAMA. 2012;307: $1151-60$

\section{Publisher's Note}

Springer Nature remains neutral with regard to jurisdictional claims in published maps and institutional affiliations. 